\title{
4 Who Speaks?
}

\subsection{Circulating aesthetics of vitalism}

\section{The culture of spontaneity}

The earliest improv troupe, The Compass, started up in 1957 at the close of what Daniel Belgrad terms the post-World War II Culture of Spontaneity. At the time, many artistic genres foregrounded a revitalization of the Human based on the ideals of freedom, equality, and the regeneration of the individual. This period, roughly the 1950s and 1960s, is traditionally named and framed as counter-cultural, which positions the discussion and its object in the political sphere of negotiability. To be able to resist in (or even transcend) the political sphere was, consequently, the prerogative of the modern white Man. As an artistic epoch, it thus speaks directly to Adorno's aim as considered in the previous chapter, even though articulated in other artistic and performative forms. According to Belgrad, the Culture of Spontaneity was not "an organized cultural movement but a loose coherence of individually unique artists, writers, and musicians" (5), a loosely circulating set of ideological and aesthetic components, variously applied across art forms and their genres - from writing to painting, from pottery to dance. Belgrad draws lines between the Black Mountain Glyph Exchange and the Beat Generation, between Charles Olsen and Merce Cunningham, Miles Davis, William de Kooning, and Jackson Pollock. He believes that even though "the spontaneous aesthetic avoided politics in the topical sense [...] it was rooted in philosophical concerns that did have political implications" (2). He presents the Culture of Spontaneity as a reaction to corporate liberal "homogenization that rewarded rule-following and attitude management as good in themselves, requiring these qualities in workers as the first step to promotion," and to the increase in mass media that propagated a liberal lifestyle: "Advertisements, mass-circulation magazines, Hollywood movies, and radio and television programs celebrated American technology and the suburban 'standard of living"” (4). Counter-cultural artists sought to oppose, even transcend, such assumed limitations by attempting to foreground an actual, pulsating, breathing reality in their work. The central methodological tool to allow reality to break into the realm of art was spontaneity, believed to bypass the ideological hinderances of a sociopolitical system:

[T] he conscious mind was the gatekeeper of social proprieties; social alternatives were therefore available first only at the unconscious level. Spontaneous composition avoided the falsifications introduced by a conscious mind that internalized ideological standards.

Ә OpenAccess. (C) 2022 Michel Büch, published by De Gruyter. (cc) BY-NC-ND This work is licensed under the Creative Commons Attribution 4.0 International License. https://doi.org/10.1515/9783110752748-005 
By offering unmediated access to unconscious thought processes, spontaneity provided a vantage point from which to question the culture's authority and created the potential for authentic communications exploring new forms of human relatedness. (29)

From this philosophy follows a political claim allegedly inherent in spontaneous art because an "aesthetics of spontaneity, in which authority derives from the artist's ability to consult his or her own unconscious, democratizes access to cultural authority" (40). This logic rests on various axioms and false assumptions that are not self-evident: a) the unconscious mind can be detached from the conscious mind, b) only the conscious mind "internalize[s] ideological standards," c) communication based on the unconscious is more authentic than conscious communication, d) the unconscious is communicable, and e) the unconscious mind exists in some hidden space and hosts universally desirable "social alternatives," and "new forms of human relatedness." In the last assumption, we can see how theorizing anti-Black abjection necessarily undercuts the whole conceptual framework of "spontaneous oppositionality." Once it is recognized that relationality in the political sphere is based on but not inclusive of Blackness, the then-fashionable romanticization of the unconscious as a new stand-in concept for a divine spirit or the soul loses ground.

However, based on these axiomatic grounds, Belgrad suggests that the Culture of Spontaneity saw the emergence of a novel kind of artist figure, "a new type of intellectual, with a different relation to America" (7), suggesting that "socially useful ideas would no longer be articulated in conventional intellectual forms, but would develop new means that did not privilege the abstract intellect" (6). This rebuke of the Cartesian body-mind-duality is central to Belgrad's argument. He foregrounds the revitalization of the Human as Man, the rediscovery of life in its breathing, pulsating form, its actual materiality as an oppositional concept against the stale rationalism of predominant sciences and arts. This dichotomy allows him to sketch out the post-World War II zeitgeist and its (neo-)vitalist philosophical foundations, from which artists in many different disciplines could draw. It is, of course, the same racialized anti-Black dichotomy through which Shusterman and Adorno articulated their theories: intriguing how arguments praising or rebuking popular culture are analogous to (or rhyme with) the romantic self-descriptions of artists and theorists of the Culture of Spontaneity. Like so many things, this parallelism makes sense only if we take anti-Blackness as a galvanizing and structuring force into account. As evaluated by Belgrad, the Culture of Spontaneity was embedded in "a formidable intellectual heritage, including the works of John Dewey, Alfred North Whitehead, and 
C.G. Jung, in addition to existentialism, surrealism, gestalt psychology, and Zen Buddhism" (6). ${ }^{1}$ All of these appear to challenge the rational subject in one way or another, arguing that there is something else, that there is more to the Human being than its rationality, that potential and truth are waiting inside the individual subject, which corporate liberalism sanctioned rather than sought. Taking the culture-specific truths-for as universal Truths, artists of the Culture of Spontaneity hoped to re-inspire Humanism, seeking to "develop an oppositional version of humanism, rooted in an alternative metaphysics embodied in artistic forms" (5). Central to this project was "a belief in the value of the unconscious mind as the locus of possibilities denied legitimacy within the prevailing ideology" (15). In this self-positioning outside or against the mainstream thought of rational/political progress and in their reliance on an invisible, mystical, psychospiritual entity or force to propel their oppositionalism, these artists had the selfassurance of being connected to something beyond the sociocultural mechanics of everyday life.

\section{Racial axioms of vitalism}

Vitalism emerged as a reaction to modern biological science, which conceived of human and animal bodies alike as soulless automata. Even though this scientific view of the body is now changing and vitalist thought has gone out of fashion at least in the academy - it had prominent proponents well into the twentieth century. Vitalist thought assumes that "living organisms are fundamentally different from non-living entities because they contain some non-physical element or are governed by different principles than are inanimate things" (Bechtel and Richardson). Aristotle is usually credited as the first scientist of vitalism in view of his principle of entelecheia, later mobilized by biologists like Hans Driesch, who theorized that the development of the embryo represented this principle in human life, "illustrat[ing] the essential difference between the living and the inanimate" (Jones 72). Vitalism has been interpreted and mobilized as "both biologistic and spiritual, naturalist and theological," and its "call to life was a call to restore imagination and creativity against the threat of mechanistic [...] psychology" (Jones 7). Vitalism sought to distinguish the Human subject from the repetition and regularity of mechanical production in both industrial developments and scientific methodologies. Donna V. Jones notes that within mech-

1 Shusterman also builds his defense of popular culture on Dewey's ideas of art as experience and philosophy at large. 
anistic discourse, some bodies were more automatic than others. She states that "the identification of the 'Negro' with the animal or the mechanical (and Descartes had already identified the last two) continues and racializes the usage of 'the mechanical' to express class contempt for repetitive, knowledge-dispossessed (rather than merely unskilled), and hence easily replaceable labor" (35). Later, central vitalist philosopher Henri Bergson refused to "understand the psyche in terms of a mechanical physis in which identical causes yield identical results as positivistically described in precise quantitative law" (29). His philosophy came as a "relief in the age of the machine" (36) - which is not to say it relieved enslaved Blacks from being considered machines with human bodies. Jones's analysis of the conceptual origins and legacies of vitalism is useful here; her underlying thesis is that "one cannot understand twentieth-century vitalism separate from its implication in racial and anti-Semitic discourses" (5). She suggests that "[v]italism was certainly the rage in the early twentieth century, and Henri Bergson was its contemporary prophet” (20), focusing on Bergson because "his philosophy had central categorial importance to European aesthetics and social thought, including its disturbing racialism” (20). She also recognizes Bergson's status as "perhaps the first celebrity philosopher [whose] concepts were ironically taken up in the new networks of mass culture, reduced, popularized and made consumable to an eager and easily bored middle class” (77).

I suggest that the Culture of Spontaneity's rediscovery of vitalist thought follows the same logic as Bergson's contemporaneous popularity. Jones's critique offers insight into the very specific ways improv perceives itself as the progressive betterment of the individual and Human soul, while reenacting and transuming anti-Blackness conservatively and regressively. Jones argues that "Bergson's mnemic vitalism is the opposite of the metaphysics of change that it understood to be" (21). Based on her analysis, we can link the ideological practice of the Culture of Spontaneity and improv to Warren's critique of a politics of hope as considered above. There is a conceptual relation between the vitalist call to life and the Culture of Spontaneity as an ideological environment in which improvisational theater flourished - it is no surprise that Schiller's idea of being human in play reverberates so powerfully in improv practice and discourse. Examples of vitalist beliefs and aesthetics abound within the Culture of Spontaneity: C.G. Jung's mysticist axioms mobilize the notion of a collective unconscious, setting free the imagination of total human universality and mystical connectedness as "participation mystique" (Belgrad 57); its more philosophical counterparts include "energy" or "force fields" (120), or other ideas of metaphysical “connection" as in Zen-influenced pottery (166). All of these posit an ideal connection to a higher power or self-abandonment - a giving in to or dissolving with- 
in a higher structure, design, or intelligence believed to inspire the individual. Regardless of (the lack of) truth-content of vitalist theory, we can safely assert that the Culture of Spontaneity as presented by Belgrad draws directly from vitalist ideas that re-create the Human subject on spiritual or mystical grounds, assuming what Abbagnano describes as "an obscure force [...] that we cannot clearly define [and which] appears to be a close relative of the soul" (118).

In Jones's argument, vitalism becomes an "expression of mysticism” rather than a philosophy or a science (72). She writes:

\begin{abstract}
The positivists in the natural sciences had little patience for fanciful postulations of a "vital agent"; it goes without saying that many scientists dismissed as vestigial and religious thinking vitalist assertions that any unseen and insubstantial agent might influence the material world [...] Excluded from traditional sciences, vitalist thought flourished in eclectic turn-of-the-century bohemian circles: the occult and alternative social movements. Madame Blavatsky's Theosophical Society, the Rosicrucians, and Aleister Crowley's Hermetic Order of the Golden Dawn had members who were attracted to the broad tenets of vitalism. (73)
\end{abstract}

The occultism and mysticism of this vitalist strand can be linked to the Culture of Spontaneity's ideology, both in content and in its heedless application. The occultists did not "engage with the details of Bergson's critique of positivism" but only "selected key concepts," most notably the idea of an élan vital, "a life force that permeates all things, attainable only through our higher intuitive faculties" (74). Followers of occultism and spiritualism were hooked, and Bergson's concept became the "philosophical evidence of a universal energy that surges through and connects all things [...] with the cosmos" allowing the Human individual to "reach higher planes of consciousness" (74). Jones claims that it was "through these spiritualist movements and not scientific debate that vitalism gained its widest exposure" (75). She further observes that the "popularization of vitalism through the occult underlines a key element of vitalist discourse: the belief in inner and hidden causal factors [that approaches a] determining essence of men." She specifically mentions Madame Blavatsky's focus on the "tapping into great reserves of "racial memory"' and her "division of the world into a complex racial hierarchy," which, of course, "mirrored the racial hierarchy of the imperial imaginary."

Jones then considers in more detail how "Bergsonian modernism proper emerges out of occultist interpretations and their focus on hidden substances, race memory, and intuition as a privileged state of consciousness" (76). Bergson's popularity arises in part from his reassertion of the Christian matrix in these occultist modern terms, reinvigorating that very matrix by offering up something else, something new that was really the same. Jones writes: 
Because his thought reintroduced the Pauline distinction between an illusory world of solid bodies (including, of course, the flesh) and the impalpable yet truer spiritual world, Bergson spoke powerfully to the crisis of the Catholic Church in the Age of Positivism. Appealing to those exploring spirituality in the nontraditional, occult movements of his time. (78)

(I would argue that postwar neovitalism, identical in its rhetorics and its ideological frameworks, functions similarly.) Bergson, indeed, had no issue claiming that "the only and complete inspiration for universal openness could be found in Christian mysticism and mythology" (81). However, there is a robust axiomatic relationship with previous, distinctly biological vitalism as developed by Driesch. Jones writes:

Bergson's own philosophy does not clearly guard against a biologically reductionist reading and in fact encourages it at many points. Having analyzed the living being to a thoroughfare through which the impulsion of life is transmitted, Bergson has the individual carry his entire past, a past that extends back to his earliest ancestors and that is augmented with the passage of time. (104)

In his Nobel Prize-winning Creative Evolution, Bergson describes memories as "messengers from the unconscious," ponders how "we feel vaguely that our past remains present to us," and mobilizes all dimensions of the past back to "the original bent of our soul" to arrive at the statement that our past "is made manifest to us in its impulses" (5). This is why, for Jones, Bergson's vitalism is mnemic. Not unlike Jung, Bergson draws from the assumption of a collective past that activates both a spiritual and a biological dimension, providing the ground for our creativity (particularly the spontaneous kind) and intuition: "The key point for Bergson is that we are free only when our act springs spontaneously from the intuition of the whole continuity of our personality, including our virtual memories, which may include the race's as well, as it has evolved up to the moment of action" (107).

This position is not self-evident and has since been disputed and derailed. Bergson can be interpreted with different foci, for example, in popular affect studies with emphasis on the preverbal. However, Jones addresses a blind spot in the interpretation of what Bergson calls "duration," implying a potentially voluntary ignorance on the part of his interpreters:

There may seem to be no room for an organic memory with biological and racial resonance or a collective racial memory of which the individual is simply a conduit, but there are clear indications in Bergson's writing that by duration he meant the whole virtual field not only of a single subject's memory but of the race to which he belonged, which now finds its home not in society but on the inside. (110) 
With racial memory as the "sine qua non of creative spontaneity [vitalism] revolution[ized] man's conception of the past - the discovery of humanity's deep, ethnological time and thus the vast possible store of virtual memory" (114). Jones thereby creates a secure link to the theoretical framework developed for this project: the continuum of the descriptive statements from theocentrism to racialized modernism. She ends by suggesting that "there is a certain isomorphism between a conception of God as an élan vital [...] and race not as a fixed essence but as a force that realized itself through ever more complex and powerful concretions” (118). She clarifies:

My argument is that once the conception of Spirit or God was so revolutionized and dynamized [...] God was soon replaced by race in this evolutionary schema, which we too often equate with social Darwinism. [...] The consequence of the whole evolutionary process was not to have fortuitously created deeply different races; rather the whole point of the evolutionary process is in the first instance to realize various dynamic racial essences. (119)

Accordingly, "once race is understood as the Bergsonian God of the evolutionary process, vitalism is no longer a form of primitivism; it is rather a form of reactionary - nay racial - modernism" (121). We must keep this in mind whenever we encounter manifestations of vitalism - whether in the Culture of Spontaneity or in contemporary improv. When improvisation as an aesthetic mode is regularly celebrated by practitioners and theorizers as a "vital life-force" (Caines and Heble 2), this is the baggage it carries. Vitalism as we know it is historically grounded in the assumption of a collectively shared life-force that connects specific groups. Applying the principle of entelecheia to this idea, we would have to deduce: whenever neo-, or post-vitalist ideas emerge, they will always be intuitive realizations of this initially racial seed of an idea. Vitalism will always be driven by a life-force, and the élan vital for white modern life (and its vitalist celebration) is Blackness.

\section{Obliteration of Blackness}

In their choices of method, style, and subject, counter-cultural artists demonstrated the impossibility of revitalizing themselves - white subjects - without recourse to non-white subject matter and methods, part of which was the appropriation of "mere cultures" (Coleman et al. 180; see III 4.1 Notes on the Rhetorics of Appropriation). The Culture of Spontaneity provided the vitalist vocabulary grounded in the primitivist fetish by linking Jung's imagined collective consciousness with Native American art. His concept "provided an influential theory linking the method of spontaneous association to the subject matter of 
primitive myths and symbols” (Belgrad 44). Psychoanalytic theory provided a legitimate pathway into the realm of universal truth, in which Native American art was assumed to be inherently and naturally situated:

The Indians [sic] have the true painter's approach in their capacity to get hold of appropriate images, and in their understanding of what constitutes painterly subject-matter [...] their vision has the universality of real art. (Pollock qtd. in Belgrad 45)

Belgrad takes the easy way out, dodging the violence inherent in the Culture of Spontaneity in a mere paragraph that defends it against cultural appropriation and instead puts forward the notion of "cross-cultural" dialogue. He argues that appropriation is "a clumsy Marxist metaphor [that] reduces all acts of cross-cultural inquiry to the single dimension of theft or dispossession, denying the variety of motives, opportunities, and effects that characterize different modes of cultural exchange" (45). I will not direct my critique at how Native American painters were exploited in the art market of the time or how political decisions ran counter to the fetishized racism directed at Native Americans. Belgrad writes about this without further analysis of the violence inherent in this appropriation of Native Americans, which always makes the white artist a "mythic hero" (61). ${ }^{2}$ But while artists of the Culture of Spontaneity sought an Other to vitalize themselves against a system that they felt atrophied their existence in one way or another, to some degree they also conceived of themselves as ethnic outsiders:

[S]pontaneity was a means for challenging the cultural hegemony of privileged AngloAmerican "insiders," giving voice to artists and writers from ethnic and social backgrounds remote from the traditional channels of cultural authority. (15)

Belgrad recognizes the pattern "of a creative artist seeking the means to cultural authority ('looking for a voice' or 'coming to authorship'), who, because of class or ethnic background, begins this search from the disadvantaged position of a cultural outsider" (40). The Culture of Spontaneity arguably performed an absolute political, philosophical, and aesthetic opposition, which speaks to and for the disadvantaged: Charles Olson was affected by "an immigrant father never quite sure of himself," Allen Ginsberg in "Manhattan's upper West Side [...] felt like a shabby, Russian-Jewish interloper from Brooklyn,” and Jack Kerouac,

2 Consider the apt expression of one Pollock biographer: "What Jackson Pollock derived from Jungian analysis - in addition to a few specific motifs, as opposed to elaborated myths - was permission to engage in his own myth-making” (as qtd. in Belgrad 66). 
"whose parents were French-Canadian, felt equally out of place at Columbia University and at the Horace Mann prep school, where he attended on a football scholarship” (Belgrad 41-42).

In terms of the existentialist reality of the Jim Crow era, Belgrad's position displays crass ignorance of the racial realities of the time just before the Civil Rights Movement. However, it serves his aim of drawing a clear-cut and purely aesthetic image of the Culture of Spontaneity without internal ambivalence or differentiation. This might be strategically understandable but does not do justice to the fact that being a "cultural outsider" is different from being a Black-racialized non-sider. While it is not inadequate to think of those artists mentioned as outsiders on the sociopolitical grid in the era of Jim Crow, this grid hovered over the sphere of Blackness and provided no positions for Black-racialized artists - except as obliterable reference points. While the gestures of spontaneous appropriation of Native American art were coded in terms of the primitivist fetish, the obliteration of Black cultural production in the form of jazz happened outside the sphere of appropriation. To indulge in Blackness was no transgression; there was no aesthetic “cross-pollination” because Blackness stood in non-relation to the Humanist subject that was being revamped. Additionally, Blackness did not provide the originary but stable meanings that Jung assumed and the artists in the Culture of Spontaneity believed they could find in the content of Native American art. As Wilderson remarks in Red, White \& Black, "as a Black I have no access to the Indian's spirit world” (46). Rather than providing meanings for the Culture of Spontaneity, then, Blackness was drawn upon in terms of libidinality and style. It is widely known, for example, that writers of the Beat Generation - most famously Kerouac and Ginsberg - modeled their art and lifestyle on what they perceived as jazz. Whether in language (from the epoque-making though nonetheless obliterative term of the "beats" to the whole array of "cats" and "squares"), attitude, lifestyle, or art (modeling literary texts after jazz improvisations or structures), jazz served as the abjected ground and Blackness as the vitalizing force from which beat poets existentially drank. Without jazz, they would not have been able to write themselves or their styles into being in the ways they did. ${ }^{3}$

Belgrad talks about what must be read as anti-Black, abjective obliteration by positing bebop jazz as a musical version of the Culture of Spontaneity alongside painting, dance, and ceramics. Slightly longer than a chapter combining ceramics and dance, the jazz chapter is the second-shortest of ten. He writes: "Bebop shared the disposition of other spontaneous art movements at midcen-

3 Norman Mailer’s 1957 essay “The White Negro” documents this. 
tury to develop an alternative to corporate-liberal culture rooted in intersubjectivity and body-mind holism," articulated through "the African American musical idiom: polyrhythm, timbre, and a structure of call-and-response” (179). With reference to Amiri Baraka's (then LeRoi Jones's) Blues People, Belgrad adds that bebop "represented a healthy separatism and autonomy on the part of the black culture" (180). Belgrad's epoch-making does not address the relevance of the 1960s in their potential to challenge "the overrepresentation of Man as if it were human,” because the particular “African American” version of his Culture of Spontaneity is framed only as a "recovery of orality [which] intersected with the racial politics of the times" (193, emphasis mine). ${ }^{4} \mathrm{He}$ even claims that "[b]eat poetry and bebop jazz shared a common cultural project: to oppose the culture of corporate liberalism with a spontaneous prosody embodying the tenets of intersubjectivity and body-mind holism" (197). However, these alleged commonalities "led the beat writers to develop strong connections to bebop jazz” (196), and not necessarily vice versa. What he idealizes as romantic "cross-pollination" or mutually beneficial "influence" is always already structured by an anti-Black framework and amounts to little more than the modern white subject drawing and profiting (libidinally and financially) on Blackness. This is even more striking because in the cultural performances and products of the time, it is all laid out in the open, as in Ginsberg's "Howl:"

Ginsberg himself modeled the structure of his poem "Howl" on the tenor saxophone playing of Lester Young, asserting: "The ideal [...] was the legend of Lester Young playing through something like sixty-nine to seventy choruses of 'Lady Be Good,' you know, mounting and mounting and building and building more and more intelligence into improvisation as chorus after chorus went on.” (Belgrad 196-97)

No more were the Beat Generation the only artists to seize on improvisation "as a potent emblem of freedom" (Banes 156). Theaters also translated and transumed Blackness-as-jazz-as-improvisation, as when taking "the improvisatory structures of jazz as a basis for dramatic form [was] an epiphany for the Living Theater" (157), ${ }^{5}$ or when Joseph Chaikin with the Open Theater "refined a particular

\footnotetext{
4 With Godzich, Wynter considers the 1960s a "first phase [...] put in place (if only for a brief hiatus before being coopted, reterritorialized) by the multiple anticolonial social-protest movements and intellectual challenges" ("Unsettling” 262).

5 Banes quotes Julian Beck: "We, who had sought to develop a style through variations of formal staging, found suddenly in the free movement and the true improvisation of The Connection something we had not formerly considered. [...] An atmosphere of freedom in the performance was established and encouraged, and this seemed to promote truthfulness, startling in performance, which we had not so thoroughly produced before" (157).
} 
technique of improvisatory sound and movement that he called 'jamming."' (Chaikin also worked with Viola Spolin's theater games, which I will consider in more detail below.)

In contrast to the appropriation of Native American art, in which the primitivist artist sought symbolic content and universal truth, Blackness-as-jazz was read in purely aesthetic and libidinal terms: jazz structures, improvisation, aliveness, physicality. Black suffering was thereby consumed and performatively extended to the artists themselves - not unlike the way in which the witnesses, spectators, and consumers at the auction block may have empathized with the enslaved Africans. While white artists sought to make art like Native Americans, in drawing on Blackness, they superficially adopted styles, language, and modalities of live improvisation and made them their own. This desire-based abjection certainly provided subject-aeffective jouissance even without generating meaningful content, of which there is none to be found in the abjected sphere of Blackness or the "banishment from ontology" (Wilderson, Red 18). It was the abjective act itself that felt politically good and aesthetically inspirational. Okiji writes that jazz has persistently been "hailed as the bearer of a democratic spirit that is manifest in its inclusiveness, its musical miscegenation, and its rejection of the composer-performer division of labor," and, in a primitivist fashion, jazz-as-metaphor is "abstracted from a black sociohistorical context to serve the needs of a spiritually bankrupt European bourgeoisie" (14-16). The Beat Generation and other artists in the Culture of Spontaneity were living in Blackness-as-metaphor, obliterating those who inhabited it in actuality. Sally Banes also recognizes that Blackness-as-improvisation did not stand alongside, or in relation to, other culturally coded aesthetic modalities at the time: "Improvisation, in particular, was seized on by white avant-garde artists as a potent emblem of freedom. Other traditions were available in the culture [...] But it was the African American tradition, particularly as manifested in jazz, that the avantgarde prized" (156). Blackness must be acknowledged as an "obscure force" and "a close relative of the soul" for the white modern subject engaging in spontaneous artistic practice (Abbagnano 118).

In fact, Belgrad's theorizing itself repeats the anti-Black obliteration that characterizes the Culture of Spontaneity. In passing, he does grant that the writers of the Beat Generation "seem to have remained willfully innocent of the racial power dynamics structuring their reception of the music." However, this line of thought and its consequences are immediately derailed into the politics of hope when Belgrad suggests that "overall they express an excited recognition of bebop as a cultural tool embodying the principles of intersubjectivity and body-mind holism" (210). What is missed is that this very excitement is part of the anti-Black structure that gives rise to what he terms "racial power dynamics." 
I have considered Belgrad here because he is one of the first to write up a comprehensive treatment of this aesthetic era, which maintains the presumption of relationality between Blackness-as-jazz and Pollock's appropriation from Native American symbolism. This relationality serves the construction of a coherent theory that explains and encompasses an aesthetic epoch and acts as an academic, conceptual accomplice in its obliteration of Blackness qua abstractification. Anti-Black abjection serves the white scholar-subject to create a coherent unity of thought. Such coherence, however, is fundamentally flawed. Belgrad does not theorize in a void. One of his sources is Charles O. Hartman's Jazz Text, in which the author comes up with this simplification: "improvisation $\rightarrow$ spontaneity $\rightarrow$ genuineness $\rightarrow$ authenticity $\rightarrow$ authority" (4). In the subsequent chapters, I will look into the usage of Blackness/improvisation-as-metaphor in more detail. At this juncture, I wish to point out the overall power of Blackness as presented in the blurb of Charles Hartman's publication:

American arts since World War II have drawn power and mystery from the ideas of voice and of improvisation. These unite in modern jazz, which is America's special contribution to world culture. But American poetry, too, has been vitally motivated by the example of jazz musicians and their ideas of personal sound and spontaneous composition.

Blackness is connoted but not explicitly named in this passage, and this gesture runs through the publication as a whole. There is no cross-pollination, but a ravenous devouring of and violent indulgence in Blackness, neither of which discursively qualify as transgression. There is no reciprocal relationship between Blackness/improvisation-as-jazz and whatever else occurred aesthetically in the 1950s and 1960s. (While it is easy to understand what a jazz text might be, like Ginsberg's "Howl," the notion of "text jazz" needs more thought.) And even if we imagine that there might be such relationality, in "many ways, the concerns of the white avant-garde were simply irrelevant to the concerns of black artists" (Banes 158). "Improvisation" has turned “American," replacing minstrelsy as the US American "signature piece” (Kopano 5), while once again offering nothing to those who created, boosted, and lived it. Improvisation has become both an emancipatory practice and a discourse that provides "further evidence of the Slave's fungibility," to use Wilderson's term (Red 19). It is laid out in the open how the "figurative capacities of blackness enable white flights of fancy" (S. Hartman, Scenes 22). This helps illuminate the power that abjected Blackness holds for the white, progressive, liberal aesthetic practice that is improvisation, which in actuality performs not a universal freedom but a self-aggrandizing universalization of the white modern subject. The obliterative argumentational move from culturally-coded jazz to a generalized improvisation is complicit in 
anti-Black discourse, be it in artistic practice or scholarly treatments. Employing abstractification to talk about improvisation as a modality without meaning (as if anything could be in-the-world without meaning) means that Blackness is continually, obliteratively abjected while the repeated abjective acts of this obliteration reassert the libidinal subject-making aeffect as white. In a sense, improv is to Blackness as the German digger is to the n-word: a consciously or unconsciously imagined blackface, a transparent "cloak of Blackness" (Watkins 87).

\section{Abjective phobia and want in improv discourse}

\section{"Slave-market bullshit"}

Early improv theater stands in a complex fear-and-desire relationship with Blackness. Its method must be read as the obliterative act outlined above; it is ahistorical and willfully ignorant to consider improvisation without recognizing its aesthetic and discursive anti-Blackness. Built on the open-source vulnerability that Blackness provides, early improv was a freewheeling, invigorating mode that anybody and any artistic genre could draw on without being accused of appropriation. Today, this abstractification has been perfected both in the artists and by theorizers; at the time, white performers openly embraced the antiBlack abjective affect that improvisation offered them, expressed in some sort of oppositionality to corporate liberalism and following the same arguments that structured the Culture of Spontaneity at large. But when it comes to metaphorizing anti-Black enslavement as a semantic space of reference for their own "flights of fantasy" (Hartman, Scenes 22) while distinguishing themselves as Human subjects from the debased Blackness, improv's founding fathers are a rhetorical class of their own. For Paul Sills - founder of The Compass, the first institutionalized improv ensemble of the era and co-founder of the Second City - "theater is responsible for the image of the human [and] the concerns of the artists are the concerns of the people." In light of corporate liberalism, Sills considers theater in its contemporaneous standard form as "slave-market bullshit" and professional actors as "vestiges of capitalist theatre" (qtd. in Sweet 18). In contrast, he expresses "a love of the authentic, the nonactor, the noble savage, the amateur" (Shepherd qtd. in Coleman 48). To transcend this "slavemarket bullshit," Sills mobilizes Blackness-as-improvisation to better society by way of reasserting a universally human subject beyond the constrictions of empirical reality: 
[It's about] the awareness that there is such a thing as the self. That the self exists. [...] The authentication of the spirit - which has something to do with the Church - is vital to the theater and is something that the theater can and must do. (Sills qtd. in Sweet 19)

Similarly, improviser Samuel Adams draws on a generalized, metaphorized enslavement stripped of its historical and racial actuality that must be differentiated from the experience of being exploited or alienated from their work (cf. Wilderson 8). He states:

I think it's a dark hour and everybody better man the pumps and get in there and get ready because this society has turned out an awful lot of slaves - people who are too afraid to move one way or another - and that could cause a lot of trouble. (qtd. in Sweet 17)

The healing of the decidedly white socio-political body through improvisational art, the hope that this is possible through vitalizing the individual who is otherwise "too afraid to move one way or another," positions improv discourse within the conceptual vitalist framework of the Culture of Spontaneity. The adoption of the metaphor and obliteration of the historical reality of Black suffering locates improv discourse in the trajectory of white people imagining themselves as Slave figures to ponder their universalized but culturally specific Humanity.

Remember how Saidiya Hartman considers the abolitionist Rankin, who sought to make Black suffering legible by way of "facilitating an identification between those free and those enslaved" in order to "make their sufferings our own" (Rankin qtd. in Hartman, Scenes 18). The same discursive identification is happening here as well, except that no Black-racialized people need to be present for improv's solipsist endeavor. Neither Rankin nor the improviser wants to be treated like a Slave. We must keep in mind Hartman's dictum that "in making the other's suffering one's own, this suffering is occluded by the other's obliteration" (19). Broeck builds on Hartman and relates this to eighteenth-century Germany; when

intellectuals rallied around the metaphor of slavery to push their own claims to self-possession and extension of civil rights, by necessity, they articulated the despicability of submissiveness as their main target. That despicability becomes latched on to the black, who remains irreversibly fixed to slavishness and thus has stood for what the white civilized human is not. The slave, from whom society must be "freed" because her slavishness pollutes and undermines bourgeois sociability, becomes the focus of rejection; "slavery" in its function to symbolize the oppression of humanity, not the white practices of enslavism in which the enlightened bourgeois actively or passively participated, needs to be transcended. This, to 18th century debates, the black in its figuration as the slave becomes useful to the extent that its horrible but distant fate enabled analogical transfer to local scenarios of emancipation from submission to the powers of lordship and nobility. ("Hegelian Maneuvers" 4) 
The abjective and obliterative metaphorization of the historically specific figure of the Black Slave is transreal and continual.

\section{Whiteface I: abstractifying the foundational jazz simile}

Despite the enslavist idea that Black-racialized people are believed incapable of theatrical improv, and in view of its chronotopical conditions of discursive and institutional autopoiesis, it comes as no surprise that improv has always and continues to be advertised, argued, and theorized with reference to jazz rhetorics on many levels. Here are some examples of the ways in which Blackness is mobilized to talk about improv via jazz:

- Improviser Alan Arkin's description of early Second City: the audiences "understood [improv] and were very excited. It was like verbal-physical jazz [with] the same kind of audience [that] appreciates good jazz musicians" (qtd. in Sweet 225).

- Theater critique Sid Smith in the Chicago Tribune: "[A] Harold is comedy in jazz riff. The payoffs come in fits and starts, if at all, and the audiences, sometimes somberly, sometimes ecstatically, gaze in empathy as these adults manufacture like children at play."

- One of the most influential improv groups in Chicago was named "Jazz Freddy" (Kozlowski 53).

- Close et al. in the improv bible Truth in Comedy: "A Harold audience will react as if they've seen a Michael Jordan slam-dunk when they watch players remembering each other's ideas and incorporating them back into their scenes" (29).

- A blog post on Amy Poehler's Smart Girls dedicated to the likeness between improv and jazz, even reversing the simile: "Like comedy improv, jazz is equally spontaneous; magic is made by an ensemble of artists collaborating around a loose structure and generalized set of rules" (Woods).

- The mobilization of jazz lingua in the discussion of improv theater, as in Wasson:

Mike [Nichols] and Elayne [May], they made jazz of [the sketch] “Teenagers," by now a standard in their songbook. The dramatic beats of the scene were the melody they riffed around, always a little differently, every time they played it. "You can't plan jazz and you can't plan improv,” Nichols said. “They must express you in the moment. You can have your central beats - those are the big laughs and the story points the scene needs but your breaks have to be there in you and come out." (51)

This selection from improv discourse is arbitrary, but can be (redundantly) added to at will. We also find such Blackness-as-jazz-metaphor in the German context, 
such as on the website of veteran improv troupe Emscherblut, which advertises by stating that "improv theater is like jazz: lively and full of energy" (my translation). Frankfurt's English-language improv Theatre Language Studio similarly advertises its classes in the vein of Belgrad's universalized and celebrated collapse of the Cartesian dualism: "Improvisation breaks down the barrier between mind and voice. It is the theatrical equivalent to jazz music" ("Why"). In providing these examples, my aim is not to attack anyone who applies the simile. Rather I wish to point out that not only can Blackness be seen here in its fungible availability for wanton application; more, it is a necessary reference to talk about improv or improvisation at all, mirroring the fact the white subject relies on Blackness to talk about itself from the beginning of modernity into the present.

In academic engagements with improv (or improvisation), the obliteration of Blackness appears to be imperative. Seeking to talk about improvised theater or improvisation, creativity, and innovation in more general terms - we academics seem unable not to draw on jazz to exemplify, decorate, illustrate, or legitimize what is really our white solipsist endeavor. Improvisation studies is a vast and expansive field covering disciplines as disparate as philosophy, health, and pedagogy. And wherever one looks, theorization falls back onto jazz - or its second-degree obliterative term, "musical improvisation." Usually, mentioning jazz aesthetics or drawing on examples from the discursive, musical, and historical world of jazz provides the ground and invigoration of that theorization. Keith Sawyer belongs to the first generation of white theorizers on improvisation. His Improvised Dialogues is one of the earliest scholarly engagements and was published in 2003 just before improv became the fast and wide-travelling concept it is now. In "Group Creativity" (the essay), he states:

The study of musical collaboration can provide insights into the study of all group creativity. To make this case, I gave examples of both music and theater group improvisations and I identified the shared characteristics of both types of group creativity. These characteristics are found in all collaboration: in classroom group discussion, in creative domains including art and science and in creative work teams. (99)

In Group Creativity (the book), Sawyer devotes an entire chapter to the likeness between improvised theater and jazz ("Jamming in Jazz and Improv Theater"). I don't want to discredit white academics who deal in improvisation in one way or another - this would be grotesque given my own position. My argument is that whenever anybody talks about improvisation as we know it within white abjectorship, we are most often talking either overtly or covertly about an ahistorical, depoliticized version of jazz, disconnected from the historical and discursive reality that brought it about. The term and concept of "musical improvisation," and higher degrees of obliterative and abjective abstractification like "group collab- 
oration," are complicit in this obliteration of Blackness qua universalization of the mode. Even writing on improv without any interest in "musical improvisation" at all draws on the Blackness of jazz, most commonly via the decorative function of introductory quotes. For example, Chris Johnston opens his The Improvisation Game with a quote by Miles Davis, going on to elaborate at length on the universally Human "self" and its potential.

Whether used as decoration, empirical matter, or legitimization, abjected Blackness predetermines everything we say about improvisation. Improv discourse is no exception but it makes rather a strong case in point. It too has always been articulated through jazz. Although almost exclusively white in its demographics (institutions, performers, audience, and performance geographies), its aesthetic ideals and affective configuration are nonetheless fully grounded in Blackness. The modern matrix ensures that this is no ethical dilemma because Black culture holds no locus for cultural production that could be stolen or appropriated:

As an accumulated and fungible object, rather than an exploited and alienated subject, the black is openly vulnerable to the whims of the world, and so is his or her cultural "production." What does it mean - what are the stakes - when the world can whimsically transpose one's cultural gestures, the stuff of symbolic intervention, onto another worldly good, a commodity of style? (Wilderson, Red 56)

In the mode of improvisation, white agents can delve into the sphere of antiBlack abjection via Blackness-as-metaphor. For the white subject, improv is like jazz but better than jazz because it is not disturbed by the Black realities that accompany jazz as a historical and cultural phenomenon. Improv feeds on and rejects Blackness at the same time. Like the political sphere of the modern West, improv is entirely inspired by, founded upon, and fueled by the very Blackness that it does not allow into the sphere it has created through, with, and on top of anti-Black abjection.

Abstractified even from jazz, improv still makes use of a specifically US discourse that has already cut paths in the national absorption of jazz. Okiji writes:

The enduring narrative of individuality in jazz sees the music as the mirror of an idealized American society - one founded on the sovereignty of the individual but respectful of the need for concessions that allow for a pragmatic democracy. [...] For the primitivist, jazz presented a course of spiritualized action, a way that decadent modern Europeans, through immersion in the experience of a jazz performance, could be cleansed. Jazz-as-democracy employs the music as evidence of American moral superiority. (16-17)

Okiji addresses the problems inherent in these discursive constructs by discussing how "black America, while contributing to 'democratic symbolic action,' 
by way of its expression in jazz, poses a direct challenge to the understanding of the terms America, freedom, and democracy" (17). In the remainder of the chapter, I will show how improv discourse makes use of these argumentational pathways even without needing to refer to Blackness in any overt way. Sam Wasson's Improv Nation: How we made a Great American Art elaborates the implicit assumptions and explicit projections of this discourse, already activated even in its title. In a harrowing line of argument, the following excerpt represents the entire network of discursive atrocity that comes with Blackness-as-metaphor when transposed from the field of jazz to improvisation, mobilizing anti-Black allAmericanness. What he writes in the register of political hope is not only a declarative statement of white ownership of Blackness but also - perhaps unintended - an acknowledgment of the depth and laterality to which the Middle Passage, enslavement, and anti-Black abjection have created the modern USA and its subjects on the affective and legislative self-conception of specifically North American US whiteness. It also offers insight into the way Black cultural production can be mobilized to imagine an exclusively white art form as indigenous to the US - at once an outward gesture toward Old World Europe and an inward gesture toward those who provide mode and material for national self-assurance, while themselves being precluded from this nationality:

"Can it be," wrote Kenneth Tynan, [...] "that the European tradition, which regards improvisation as a means to a perfect, fixed and stylised end, is fundamentally inimical to the American tradition, which regards improvisation as an end in itself - as the key, in fact, to a new kingdom of theatrical entertainment? If so, we had better reconsider, for our way of thinking excludes from the theater the kind of invigoration that jazz brought to music." Unimaginable where speech is not free, improvisation is [...] the prodigal son of the First Amendment. [...] It is the tree and fruit of the American mind.

Americans have always been improvisers. "In the language of the Declaration of Independence, for example, Americans accorded themselves the right to revolution, that is, the right to create new forms," writes Professor Kerry T. Burch. "The US Constitution's amendment process similarly codifies permanent revisability as a defining feature of our democratic-inspired political culture." Americans are a work in progress, an ensemble revolution, making it up as we go along. Changeability - the intended imperfection of our foundational documents - opens the way to a more perfect union. And individuals: "Because of the chemistry and the way people were playing off each other," Miles Davis wrote of jazz collaboration, "everybody started playing above what they knew almost from the beginning. Trane [John Coltrane] would play some weird, great shit, and Cannonball [Adderley] would take it in the other direction, and I would put my sound right down in the middle or float over it, or whatever.” Through improvisation, they made each other better. Giving themselves over to syncopation, playing, literally, off-beat - term jazz shares with humor - they discover new beats. Surprise and variation, touchstones of improvisation, are requisites of both, amendments - to the melody, the scene, the "law" - permissible only where speech is free. "I think what we look for," explained jazz pianist Bill Evans, 


\begin{abstract}
"is freedom with responsibility." Without that freedom, we would be perennially scripted, locked into quarter-note time, unable to evolve new rhythms out of those conflicts that arise from our melting pot morality or, as Del Close described it, the "democratic mess." We can clean it up with improvisation. (84-85)
\end{abstract}

There is much to unpack here, but in this context, I focus only on those aspects that bring out my argument. First, we must recognize how improv adopts the function of blackface minstrelsy in the nineteenth century in being mobilized for national self-assertion - most explicitly in opposition to Old Europe by drawing on the anti-Black abjective libidinal economy. However, unlike "America's popular culture signature piece," as Kopano describes black-faced minstrelsy (5), the all-American improviser can "indulge the desire to escape the binds of 'civilized' behavior" (Watkins 100) without putting on burnt cork. While also "modeling himself after [...] a black man of [...] natural freedom," the white improviser attains this lively all-American Blackness by the cover of the improvisational mode. The white improviser does not pretend to be Black anymore; the "cloak of Blackness" (Watkins 87), though aeffectively Black, has become discursively transparent while still enabling (and allowing) the artists "to cast most of their own inhibitions to the wind" (Watkins 87) - which is precisely what people cherish improv for, what they like, why they are willing to spend a lot of money on it. Trading in improv (offering classes and shows) is thus trading in anti-Black affect. In other words, the white improvising subject feels Black without necessarily being aware of it, drawing on Blackness without knowing it consciously. In the popular cultural anti-Black sphere, improv has obliteratively transumed Blackness to the degree that it has become possible to act Black without looking Black. Improv-as-Blackness is a multidimensional representation of the American cultural entity entirely grounded in anti-Black abjection: "Blackness" turned "jazz" turned "musical improvisation" turned "improvisation" turned "Americanness." While keeping the affective experience of Blackness in action, we do not need to examine this logic or its history; we white people have always been in a position to act Black without being Black, but no longer recognize when we're doing so.

Part of what makes the passage from Wasson so disconcerting is that he seems to be well aware of how he mobilizes Blackness. He alludes to Barack Obama's "A more perfect Union" speech from 2008 and (obligatorily) quotes Miles Davis. He misses the fact that the term "off-beat" is not merely shared by humor and music, but emerged in a specific cultural context later framed by white scholarship as the Culture of Spontaneity, which in itself performs anti-Black abjective gestures and motions. Like the term "improv," the notion of "off-beat humor" is secondary to and derivative of jazz terminology. For Wasson, America 
(he does not differentiate between the two continents) is as distinctly Black as jazz was for Adorno. While the latter aggressively seeks to destroy American Blackness, Wasson devours it. Where Adorno defends the European subject in his anti-Black abjective argument against jazz and improvisation qua Blackness-as-metaphor, Wasson defends the American subject in his anti-Black abjective argument in a progressively hopeful mobilization of the same concepts. Both run on anti-Black abjection nonetheless. In referencing the Declaration of Independence (both in content as well as inbuilt modality), Wasson willfully and consequentially leaves out historical Black enslavement. It would be too much to ask this author to read the American ideals of egalitarianism and freedom of speech as racialized concepts. Wasson's argument is so blatantly driven by anti-Black abjective jouissance, by the desperate need to be "a good man or woman of one's kind" (Davis qtd. in Wynter, "Unsettling” 271) - that is, a white subject of the United States - that it can almost be taken at face value. We might indeed, as Wasson suggests, understand a universalized improvisation as the "tree and fruit" of the American mind.

Strange fruit, though.

\subsection{Intuition and abjection}

The concept of intuition features largely in Bergsonian vitalism and its later transumptions in the Culture of Spontaneity and improvisation. Improv performers would rejoice in recognition at statements like this one:

Our intelligence [...] can place itself within the mobile reality, and adopt its ceaselessly changing directions; in short, it can grasp it by means of that intellectual sympathy which we call intuition [...] To philosophize, therefore, is to invert the habitual direction of thought. (Bergson, Metaphysics 69-71)

Jones describes Bergsonian intuition as "absolute in its promise - the transcendence of the seemingly impermeable split between subject and object" (89). Rather than taking up vitalist intuition in its aesthetic-ideological context as a way out of mechanistic, corporate, consumerist, or other restrictions, I look at it from the viewpoints of neuroscience and embodied cognition. Intuition structures our behavior in many situations - for example, when we cannot seem to make a rational choice because there are too many variables, or because we do not have time to weigh the options carefully. ${ }^{6}$ Intuition is the gut feeling

6 See further Lehrer's How We Decide (2010). 
that helps us to act anyway, and to at least assume that we know "the next best thing to do" (Claxton 65). In current usage, by "intuition" we generally mean the ability to make decisions or acquire knowledge without understanding or knowing how we came up with it. It should thus be of no surprise that the concept derives from and (still functions within) an esoteric or religious framework that allows us to think of ourselves (our bodies) as more than we (they) are. If we can know without understanding how we know, this logic suggests, we are fundamentally connected to a hidden power or a divine design through intuition. (The unconscious and its mobilization in the Culture of Spontaneity can be read as a transumption of this hidden power.) Many shades of this mysticized intuition can be observed in improv discourse, and in this section, I look at intuition as a generative concept for improv practice and discourse. I consider excerpts of Viola Spolin's originary and influential writings on theater games, and will subsequently argue with Claxton and Damasio for intuition as a pathway to our biopsychological programs rather than a spiritual or moral core, locating it on the sociogenic brink of being human as mythoi and bios. I will develop a conception of intuition fully grounded in the psychosomatic libidinal economy of the body and thereby immediately related to anti-Black abjection.

\section{Intuition and the unconscious in traditional improv discourse}

During the Great Depression in Chicago, pedagogue Viola Spolin worked with "ghetto children from the West side streets" (Coleman 23). In her everyday practice, she developed numerous theater games, which were then collected and published as Improvisation for the Theater. The book has been called "seminal" (Coleman 23), and is often referred to as the "bible of improvisational theater" (Spolin back cover). Unlike the contemporaneous and popular Stanislavskian or Strassbergian methods, which were influential in the psychological realism of the stage, Spolin's notion of improvisation focuses on play. It is "basically nonverbal" and "does not emerge from the logical sequence of language, only from the sequence in which objects, the environment, characters, relationships, points of view, and personalities appear out of spontaneous interplay." Each one of Spolin's 222 listed games “pinpoints another outlet off the mainstream where intuition flows - not through the individual mind or ego but through human connections in physical space” (Coleman 27). 
The influence of the "high priestess of improvisation"7 on US improv cannot be overestimated (Coleman 95). Her son Paul Sills used her games in his work with the early Compass; whenever the group felt uninspired, Spolin's workshops reinvigorated them in their theatrical improvisation. What had been developed as children's games became a constant resource for training actors in improvisation. For them to become stageworthy involved training and developing their intuition:

Intuition is often thought to be an endowment or a mystical force enjoyed by the gifted alone. Yet all of us have known moments when the right answer "just came" or we did "exactly the right thing without thinking." Sometimes at such moments, [...] the "average" has been known to transcend the limitation of the familiar, courageously enter the area of the unknown, and release momentary genius within. (Spolin 3)

Departing from the idea of the romantic genius selected by nature, Spolin suggests that, when trained the right way, everybody has the potential of such ingenuity. Such intuition, Spolin continues, "can only respond in immediacy [to] the moment when we are freed to relate and act, involving ourselves in the moving, changing world around us" (4). Her conceptual framework thus speaks to the subsequent assumption by the Culture of Spontaneity that immediacy and spontaneity provide a portal that takes the individual beyond sociality, culture, language, representation:

Through spontaneity we are re-formed into ourselves. It creates an explosion that for the moment frees us from handed-down frames of reference, memory choked with old facts and information and undigested theories and techniques of other people's findings. (4)

Unlike most of the art Belgrad framed as the Culture of Spontaneity, however, Spolin does not rely on a kind of mystical entity to which one can connect, except the belief in a humanity that we all share. For her, intuition denotes something inherently human, "that area of knowledge which is beyond the restrictions of culture, race, education, psychology, and age" (19). This does not mean, however, that Spolin was not sympathetic to esoteric vitalism. In fact, according to Coleman, Spolin was known to "compare her own territory to that of 'Madame What's Her Name:"”

Blavatsky, the Russian theosophist and mystic [...] shared Viola's view that human consciousness - the spirit - can transcend rational intelligence into a state of divine telepathy,

7 Notably, the head of the iO, Charna Halpern, claims this title for herself as she felt anointed by Del Close to that very position (Art by Committee 108). 
synergy, oneness and connection with the cosmos, nature, mankind, God, and all the demons, dybbuks, metaphors, and mythologies that throb through the universal mind. (Coleman 30)

Recall Jones's assessment of Blavatsky's “division of the world into a complex racial hierarchy” as a mirror of a Eurocentric racial hierarchy (75-76). Spolin's awareness of and association with this theosophical fetish resonates with the contemporaneous and popular fascination with Eastern philosophy and Western mysticism. In opposition to the dictatorial rule of the "system," it did not matter much whether the way out was Taoist, mysticist, or "the Buddhist thing" (Spolin qtd. in Coleman 32). As a transumption of such theological ideas of something beyond, Spolin's rhetoric of awakening develops a mysticism of spontaneous transcendence, of self-discovery through self-abandon. Improvisatory play is construed as a potential pathway to such transcendence, reaching out into the world beyond the game and helping players discover who they really are:

Growth will occur without difficulty in students because the very games they play will aid them. The objective upon which the player must constantly focus and towards which every action must be directed provokes spontaneity. In this spontaneity, personal freedom is released, and the total person, physically, intellectually, and intuitively, is awakened. This causes enough excitation for the student to transcend himself or herself... (Spolin 6)

What in earlier (occultist, spiritual) variants demanded spiritual leadership here becomes a cause and effect logic, whose lacuna around spiritual existence can simply be ignored by imagining a "total personality [...] to emerge as a working unit" (6). What would earlier have been framed as some connection with a spiritual entity becomes the "discovery of the self" (6) or "deeper self-knowledge" (26). These fantasies persist into the present, as in Johnston, who thinks that "the medium of improvisation, properly handled, has the capacity to show us to ourselves" (6).

From the very beginning of Chicago improv, playing theater games originally developed for children was understood to allow adults to return to a realm with which they felt they were no longer connected. Playing these games made them feel they were undergoing mystical experiences; improvisors "experience the practice as a high, a form of bliss" (Coleman 28). Mike Nichols remembers that "once in a while you would literally be possessed and speak languages you didn't speak [...] I don't mean to sound mystical but such things did happen," and for practitioners like Richard Schaal, theater games are "spiritual," “infinite," “everything” (qtd. in Coleman 28). Spolin's system needs no teachers, no authority. At a time when gurus abounded, Spolin did not claim for herself the mystical authority of leadership that earlier variants of vitalist esotericism 
had. Her playful, improvisatory approach to activate, train, develop, and free human intuition dispensed with all notions of authority: "All words which shut doors, [...] attack the student-actor's personality, or keep a student slavishly dependent on a teacher's judgment are to be avoided” (Spolin 8, emphasis mine).

\section{The individual and collective unconscious in improvisation today}

Spontaneity and intuition have always been central to improv discourse. The ground for intuitive decision-making has often been called unconscious, celebrated in improv as the sphere of real, originary, and pure creativity. The authors of Truth in Comedy suggest that the "unconscious is a lot smarter than most people think," and that "as the players grow more experienced on stage, they discover they have an inner voice which, when followed leads them to interesting twists in the scene":

The ego is the part of the mind that hangs on to preconceived notions about scenes, so the best improvisers always strive to overcome their own egos. They've learned to trust their inner voices to their unconscious right choices. (Close et al. 91)

Whether we conceive of the unconscious in a traditional psychoanalytic way or apply it as a shorthand for biochemical happenings in the body, it always provides the ground for intuitive action and behavior. Consciousness is assumed to be an obstacle that must be overcome for the improviser to be free to improvise: "Egos have to be sacrificed for the good of the game" (Close et al. 40). The ideal improviser is thus a medium in the strict sense of the term, a "channeler" who articulates content that otherwise lies beyond them. The notion of "flow," which looms large in improv studies, describes a state in which the improviser is no longer bound to the restrictions of consciousness but draws from the pool of unconscious intuition. The term is mainly connected to the work of Mihály Csíkszentmihályi, who uses it to refer to "the holistic sensation that people feel when they act with total involvement" (150). In this state, "action follows upon action according to an internal logic that seems to need no conscious intervention by the actor" $(150-51)$. Acting in flow is thus based on the notion of intuition, in that intuition tells us exactly what to do without rational interference. It provides natural(ized) reactions to a given setting or configuration. If play takes us beyond consciousness, intuition is how we decide when we're in that space of play, and flow is the feeling we have when we play.

While flow is something an individual is assumed to have or to be in, the notion of "group flow" has been developed by Keith Sawyer to refer to collective experiences: group flow sets in when "a group is performing at its peak" 
("Group Creativity" 95). Sawyer differentiates his collective-based concept from Csíkszentmihályi's original notion by suggesting that the latter "intended flow to represent a state of consciousness within the individual performer, whereas group flow is the property of the entire group" (95). ${ }^{8}$ He continues: "In group flow, everything seems to come naturally; the performers are in interactional synchrony. In this state, each of the group members can even feel as if they are able to anticipate what their fellow performers will do before they do it" ("Group Creativity" 95). Seham too notes that many "players form deep, unspoken connections with teammates" and achieve "a state of unselfconscious awareness in which every individual action seems to be the right one and the group works with apparently perfect synchronicity” (64). In improv lore and discourse, the term "group mind" is commonly used to express this, as described in Truth in Comedy:

\begin{abstract}
After an improviser learns to trust and follow his own inner voice, he begins to do the same with his fellow players' inner voices. Once he puts his own ego out of the way, he stops judging the voices of others - instead, he considers them brilliant, and eagerly follows them [...] When a team of improvisers pays close attention to each other [...] a group mind forms. The goal of this phenomenon is to connect the information created out of the group ideas - and it's easily capable of brilliance. (Close et al. 92)
\end{abstract}

The iO claims that it holds the key to achieving "group mind," having developed forms that more or less ensure it. The company's owner Charna Halpern claims in Art by Committee that "We have the power to [...] provide the audience with a religious experience” (17). This rhetoric plays a large role in iO's perceived cultishness because it resonates with the ideas of spiritual leadership, as can be drawn from this section in Close et al.:

The [iO] ImprovOlympic workshops constantly prove that a group mind can achieve powers greater than the individual human mind. Scenes created have turned out to be prophetic, and ESP has actually occurred on stage. Players are able to speak simultaneously, at a normal rate of speed, saying the exact same thing, word for word. Some teams become oracles on stage, answering great questions about the universe, one word at a time, leaving the audiences chilled and astonished. Audiences have witnessed the group mind linking up to a universal intelligence, enabling them to perform fantastic, sometimes unbelievable feats. [It] almost seems like they are tapping into the same universal consciousness. (93)

8 Sawyer suggests flow can be owned. The ambiguity of the term "property" obviously contradicts the idea that flow is unpredictable, ephemeral, and intangible. Sawyer has no issue with the oxymoron "emergent property." However, only the modern white subject is in the epistemological position to own what it previously defined as unownable. 
Not many improvers believe in extrasensory perception nowadays, although the trope is still mobilized: "By committing to focusing outward and following the group, we will look to an audience like we have ESP and create that unique improvisational magic" (Gantz). However, the idea of a group mind remains in full effect. For Mark Fotis, it means that "all players [...] are working toward the same goal by opening their awareness and creating one group mind that encapsulates each individual; it is 'e pluribus unum' exemplified” (9). The bloggers of People and Chairs: The improv blog with attitude are also fascinated: "Group mind, in my opinion, is one of the coolest things in improv. When group mind is present, you don't steer scenes: you're compelled to move, together. It's about letting go of consciously thinking and being in a state of flow" (Smallwood and Algie).

The idea of support functions as a technique to achieve the higher aim of tapping into a supra-individual unconsciousness because group mind can only be achieved by accepting and agreeing with the ideas of one's fellow players and scene partners. This imperative - though highly problematic - is necessary to produce non-contradictory worlds on the stage. Non-contradictory creativity and creation based on action in flow (that is, on intuitive action) can be understood as the aim of an ideal collective improv scene that also involves the audience. ${ }^{9}$ The implications here are obvious, and Seham asks the right question: "When the group works as one mind, whose mind is it? How does the seeming rightness, inevitability, and spontaneity of improv mask the unmarked power of hegemony" (65)? Whatever truth-for a group can create or articulate collectively is based on a shared ground of knowledge and ignorance specific to that group. Even Johnston, who otherwise concerns himself with the potential of "another self to be seen, and improvisation [...] conjuring up the exercise” (6), recognizes that the discursive articulation of a group is not necessarily universal. Yet he cannot do without at least hinting at the idea of collective unconscious:

Improvisation can go further to bring forward themes and images arising from a group working together collaboratively. Arguably, there is a connection here with the notion of a collective unconscious, the existence of a body of shared psychic material that becomes apparent only in its expression. The notion holds particular appeal when a group of people with similar backgrounds commit themselves to an imaginative exercise. The material

9 Amy Seham quotes Lisa Trask, "the first woman team coach" at iO:

I firmly believe, that the audience can be in that group mind too - they're only seconds behind you. We get people screaming "Yes!" because it rings true with them... because they knew it. They don't know how they knew it - but when we said it, it was so. And that's why it's so gratifying for an audience member to see it. [When they] see a good improv show, the audience walks out just as high as the performer does. (65) 
emerging from their endeavors can often be identified as saying something about the predicament or life situation of that group. (11)

If a group imagines or experiences itself in group mind or flow grounded in intuitive (or instinctive) behavior, can we reframe that intuition without resorting to the mystical or taking too humble a position toward the unconscious? In improv, the experience of group mind and flow, whether collective or individual, necessitates the mobilization of intuitive behavior - actions we do not consciously rationalize in advance. I suggest we turn to intuition as a core concept to describe improv praxis and see where it takes us. Let me offer another excerpt about group mind from Truth in Comedy (Close et al.) which, to my mind, holds more truth than may have been understood or intended:

There is an empathy among the individuals involved, almost an instinct. The members exist to serve the needs for the group, much like the Inuit Indians who place themselves in a group trance to attack a polar bear or a whale. (92-93)

Here, flow does not serve the emergence of truth via group mind or collective creativity, but instead addresses a culturally specific group activity aimed at destruction and devouring, drawing on a non-white "mere culture" (Coleman et al. 180) to describe that. Such instinctive empathy is directed against a common enemy to kill and enjoy for sustenance, for survival, or - in the case of improv for fun. Below, I will consider whether and how a culturally specific white intuition can be conceived, and how far this would take us. ${ }^{10}$ How do can we productively frame the diffuse concept of the unconscious?

\section{The cultural specificity of white intuition}

I am not the first to address the violent romanticism of group mind. Amy Seham raises some important points for debate in her critique of improv:

10 Where improv discourse still has not entirely rid itself of the mysticist framework, of the belief in something higher, in the academic world, the concept of "emergence" has taken the place of collective unity in the Jungian vein. While there might not be a universally shared pool of truthful content, some unknown source, some never-to-be-understood unconscious to be drawn from, the concept of emergence similarly "frees" the individual of individualistic knowledge. German improv scholar Gunter Lösel relies and elaborates on the idea of emergence throughout his Das Spiel mit dem Chaos. He takes the notion from Sawyer's Improvised Dialogues: Emergence and Creativity in Conversation. 
Because the spontaneous performer seems not to have time to construct images consciously, the social construction of these images seems invisible. Through improvisation, these representations come together, as if by magic, in narratives that appear natural, inevitable, and true, but they are more likely to be drawn from archetype, stereotype, and myth. (xxi)

It is false to assume that spontaneity leads toward "social alternatives," as Belgrad puts it (29). The resonance of several individuals interacting with one another can only appear magical or be experienced as mystical if a shared sociocultural ground already exists. However, I suggest that we take the unconscious more at face value than Seham does. I posit that the emergence of stereotypes is not based on conscious ignorance but represents only the most superficial result of a fundamental libidinal structure also known as the unconscious, which, as Lacan states, is structured like a language. Consider Lyotard in Libidinal Economy:

Theatricality and representation, far from having to be taken as libidinal givens, $a$ fortiori metaphysical, result from a certain labour on the labyrinthine and Moebian band, a labour which prints these particular folds and twists, the effect of which is a box closed upon itself, filtering impulses and allowing only those to appear on the stage which come from what will come to be known as the exterior, satisfying the conditions of interiority. (3)

Being human, we create theatricality and linguistic representation as the topography of our unconscious, which we need to understand along with Lyotard's extended metaphor as the concrete sociogeny that defines our culturally specific and biochemical being in the world. Our libidinal structure and topography filter external impulses according to the linguistic rules of what has been represented to our consciousness as affective linkages. The selection is based on criteria of "interior satisfaction." We can take this as an elaborate metaphor of how our body-brain functions and how anti-Black abjection partakes in the workings of Lyotard's Moebian band. Considering the unconscious in this way will help us gain a more productive understanding of it.

Intuition helps us short-circuit the complex rationale our body goes through when deciding on "the next best thing to do" (Claxton 10). Our whole body always already (thinks it) knows the best action and behavior in any given situation. Damasio's concept of covert somatic markers ensures that we do not rationalize or judge the possible outcomes of that action, but instead let the body decide what to do. Because the body does so not virtually but in actuality - organs, neurotransmitters, blood pressure, and so on - it feels natural, if any interpretable feeling reaches consciousness at all. Very often it does not. However, as Damasio writes in Descartes' Error, this "does not mean that the evaluation that normally leads to a body state has not taken place [...] Quite simply, a signal 
body state or its surrogate may have been activated but not been made the focus of attention” (185). This is how he defines unconscious bias:

[Triggering] an activity from neurotransmitter nuclei, which I described as one part of the emotional response, can bias cognitive processes in a covert manner and thus influence the reasoning and decision-making mode. (185)

Damasio, then, speaks of intuition when somatic states "operate covertly, that is, outside consciousness" (191). The whole biochemical process that leads to action or inaction in the individual does take place, but it never reaches consciousness. This can make it appear "mystical" at times:

The explicit imagery related to a negative outcome would be generated, but instead of producing a perceptible body-state change, it would inhibit the regulatory neural circuits located in the brain core, which mediate appetitive, or approach behaviors. [...] This covert mechanism would be the source of what we call intuition, the mysterious mechanism by which we arrive at the solution of a problem without reasoning toward it. (191-92)

This is a much more graspable notion of intuition than the esoteric one considered above. Yet the latter still looms large in improv. We must once and for all get rid of the romanticist view that an individual tapping into his or her unconscious will find something objectively truer, something more universal there than anywhere else. A group of individuals will not find something that they do not already know and share collectively - which, on some level, improvisers have always known and stated. Consider Mike Nichols, the first big improv star whose success came with partner Elayne May: "When you have to make things up on the spur of the moment, you gravitate very quickly to the person who understands you most easily" (qtd. in Wasson 37).

Claxton reminds us that intuition is based on experience and is therefore fallible (278). "Experience" here refers to any acquired knowledge or language system and does not mean that, for example, phobic Blackness is based on actual experiences with Black-racialized people. Rather, its ground can lie in an observed role model's abjective reaction to Blackness, or it might be learned from the ways in which Blackness is (not) narrativized in the media or other representational spaces. It does, however, involve the fact that Blackness both structures and is being mapped onto the abjective sensation in the body and the way that this sensation, as subject-aeffect, motivates white behavior to become "a good man or woman of one's kind" (Davis qtd. in Wynter, "Unsettling” 271). The learning process begins in the introduction to a semiotic system, to the language that this specific order provides - a process in full swing when the infant starts to play. If that semiotic system is ultimately grounded in, structured by, 
and continually reenacts the dehumanizing praxis of anti-Black abjection, this will necessarily prefigure intuitive responses. The cultural specificity, the learnedness of actual biological affectation, is a crucial point in Wynter's "Toward the Sociogenic Principle.” She writes:

\begin{abstract}
But do we, as humans, experience pleasure and satisfaction only from biologically appropriate behaviors? Does the opioid system in our case function only naturally? If [...] the answer to both of these is a yes, then how do we account for the fact, that, as the description of the early seventeenth century Congolese reveal, what was subjectively experienced as being aesthetically "correct" and appropriate by the Congolese (their qualitative mental states of dynorphin-activated aversion on the one hand, and their beta-endorphin activated "pleasure and satisfaction" states on the other) was entirely the reverse of what is subjectively experienced by western and westernized subjects as being aesthetically correct and appropriate? How can the same objects, that is, the white skin color and Caucasoid physiognomy of the Indo-European human hereditary variation and the black skin color and Negroid physiognomy of the African/Congolese human hereditary variation, give rise, in purely biological terms, to subjective experiences that are the direct opposite of each other? [...] Are we not in both cases dealing here with the processes of functioning of two differently culturally programmed opioid systems, two different senses of the self of which they are a function? (51-52)
\end{abstract}

When encountering elements of Blackness that have been somatically marked as abjective spaces or modes and that therefore constitute white people's primary affect, providing a ground and projective space for cathecting fear and desire, the white subject-body short-circuits consciousness to figure out intuitively the next best thing to do: abject it.

This is where somatic marking comes in. The active form of the verb reveals that it is not the external object that makes an imprint on the perceiving subject's body. On the contrary, it is the subject's body that marks what it perceives by attributing to it a specific biochemical makeup. Damasio reminds us that "a feeling about a particular object is based on the subjectivity of the perception, the object, the perception of the body state it engenders, and the perception of modified style and efficiency of the thought process as all of the above happen." (147-48, emphasis mine.) Wynter and Damasio intersect here: there is nothing naturally ontological in the object (or subject) as such, but the subject's biological reaction is still real. Phobic Blackness, then, must be seen as a result of the solipsist yet anti-Black abjection of our unconscious when it intuitively decides for us what to do next. This is based on covert somatic marking without representing the activated body loop or neural circuitry to consciousness:

The explicit imagery [of the chemical body-map] related to a negative outcome [of a scenario triggered by perception or imagination] would be generated, but instead of producing a perceptible body-state change, it would inhibit the regulatory neural circuits located in 
the brain core, which mediate appetitive, or approach, behaviors. With the inhibition of the tendency to act, or actual enhancement of the tendency to withdraw, the chances of a potentially negative decision would be reduced. (Damasio 187)

Covert somatic marking supports our natural avoidance of certain anticipated body states (such as the dissolution or threatened destruction of one's subject status in the presence of Blackness) and stimulates acting to attain jouissance qua the assertion of one's subject status. The marking is prestructured and preprogrammed in our bodies and comes out as intuitive action. Given that white fear and desire are so bound up with anti-Black abjection, white intuition necessarily is too. Abjective reactions to Blackness, driven by fear or desire, are intuitively correct for the white subject - and it is of no concern whatsoever what rationalizing that reaction would lead to, or how contemporary superficial morality would judge it. One could go as far as to say that the more anti-Black abjection a white subject enacts, the more integrity it has as a subject of the modern West, the more efficient is its body-brain's computational program. These general ideas about locating the cultural specification of white intuition on the grounds of the sociogenic principle and the praxis of abjection may appear counterintuitive or in conflict with the idealized meaning of the term. As discussed above, I suggest we need to think about intuition not as natural but as naturalized, following Wynter's post-Fanonian mobilization of the sociogenic principle as a culturally specific biochemical or psychophysical setup in the body-brain, which conditions us to know or react intuitively to possible solutions to problems of the body-brain's imbalance in favor of psychological as well as physical homeostasis.

What do we make of this in our consideration of improv? I suggest a heuristic differentiation into three fields: a) the intuitive creation of dehumanizing content, b) the unmaking or propertizing of scene partners, mostly while creating that content, and c) the way in which our white modern unconscious biochemically grounded goings-on in the body (bios) are structured by a mythological (mythoi) dichotomy that divides the world along racial terms into the high and the low, the rational and the irrational, the civilization and nature.

\section{Whiteface II: the abjective ground of being an improviser}

We might frame some intuitive, improvisational decisions as white ignorance, but the many instances of Black-racialized improvisers who are not only reduced to stereotypes but propertized, made immovable, or entirely dehumanized on stage speaks to something more. When Dewayne Perkins is approached the 
top of a scene with the statement "Now put on this noose," he is not stereotypically depicted as a representative of another culture. He is treated as an enslaved, propertized, thingified, and killable body. When Kimberly Michelle Vaughn is told she will have her "skin stripped off" by white German scientists or Patrick Rowland is "unmade" on stage (both in personal conversation), it is not about stereotypes or misrepresentation. It is about Black bodies used as manifest extensions of a fictional abjected Blackness that the discursive matrix of the modern West holds for them. White intuitive reactions like that do not speak to a lack of rational knowledge, as elaborated by Mills in "White Ignorance." Rather, they reveal the hardwired shortcut for our white subjects' (shared) neural circuitry.

There is a final, more primary dimension here, which I can only conceive of as speculation. At first glance, it appears so primal that we can do without theorizing its cultural specificity. What I suggest feels contrived, I think because I too am located within the "cognitive dilemma" addressed by Wynter when she describes how "in the same way as the bee can never have knowledge of the higher-level system that is its hive, we too can in no way normally gain cognitive access to the higher level of the genre-specific autopoietic living system" ("Catastrophe" 32). As an escape, Wynter posits with Césaire "the study of the Word/ mythoi," where mythoi become an external ground from which we can see how our biological being exists. What I am pursuing here is, in fact, an attempt to follow the consequences of such a study of the Word, deconstruing the mythoi that gives rise to our being human as bios, which takes me right back to the modern matrix and the chain of transumptive descriptive statements of what it means to be human in historical and contemporary modernity, most prominently the dichotomous way we think of ourselves in the world. I propose that the need for such coherence, the symbolic ground for the biochemical sensations that pertain to the subject-aeffect, as well as the possibility and capacity of attaining it, is a result of the fact that our modern descriptive statement is structured as a dichotomy. This Manicheanism, even if heuristically separated from its racial symbolism, is not natural. It is a semiologically arbitrary fixation of the Human that, drawing on the Platonic postulate to realms of absolutes, sets up an axiomatic stability where there is none. The white modern self is stabilized based on a split psyche that does not exist outside a racial grammar. Therefore, whatever libidinal need ensues from this Manichean split is always already racialized. If, as I argue, the subject-aeffect functions to bridge this split temporarily, there is no subject-aeffect that is not initiated or triggered by an act of anti-Black abjection. Were it not for the Blackness that white modernity has conceptualized as a "state of nature" (Mills, Contract 10), we would not be able to conceive consciously (or to dream unconsciously) of the state of nature to which we aspire when playing 
or improvising. (Again, this is something beyond the cultural phenomenon, the historical and contemporary actuality of improv, which is related to it, but to which it is not reduced.) Were it not for our racialized and abjective libidinal economy, the racialized ground of our psyche, we would not need to experience this specific sensation in this culturally specific way. The grammar would be different. We white subjects would speak, do, and feel different content in a different language. In other words: if the need to improvise - or better, the joy that improvisation brings - did not come from the same place as the desire to be Black and the urge to destroy Blackness, if we did not live in the anti-Black Manichean dichotomy of what it means to be human, improv would not fill this specific need. It would not have such desires projected upon itself. It simply would not be. ${ }^{11}$

From this vantage point, the practice of improvisation no longer refers only to a Black-coded homogenizing descriptor for cultural activity. White performance of improv is no longer obliterative on the grounds of cultural practice. Acting on Manichean anti-Black intuition through the mode of improvisation becomes the very fabric of white modern subject-making. This experience of self is not contingent or coincidental, not like but structurally identical to the somatic state of anti-Black abjection. We can look to Damasio to endorse the idea that the physical sensation is, in fact, the same:

\begin{abstract}
It is plausible that a system geared to produce markers and signposts to guide "personal" or "social" responses would have been co-opted to assist with "other" decision making. The machinery that helps you whom to befriend would also help you design a house [...] From an evolutionary perspective, the oldest decision-making device pertains to basic biological regulation; the next, to the personal and social realm; and the most recent, to a collection of abstract-symbolic operations under which we can find artistic and scientific reasoning, utilitarian-engineering reasoning, and the developments of language and mathematics. But although ages of evolution and dedicated neural systems may confer some independence to each of these reasoning/decision-making “modules," I suspect they are all interdependent. When we witness signs of creativity in contemporary humans, we are probably witnessing the integrated operation of sundry combinations of these devices. $(190-91)$
\end{abstract}

In this logic, any given somatic state may be multifunctional because the same "machinery" works and functions for different emotions. Engaging with (micro) elements of Blackness causes a somatic state for the white subject-body that is

11 Improviser Joel Boyd's statement that “If this issue was solved or wasn't solved [white people's] lives would be the same" would then be wrong (personal conversation). If this issue was solved, we white people would not exist as we do now. But, speaking with Warren, solutions are antithetical to the politics of hope. 
identical to or overlaps with the somatic state of play, creativity, or intuition. Because of this overlap, doing improv as a self-experience equates with the somatic state of anti-Black abjection without the subject knowing it. This may be why intuition is so incredibly quick when encountering Blackness, and why people get so creative.

Acting on intuition is thus not reducible to a cultural project of feeding on and obliterating Blackness-as-improvisation or white people monetizing Black cultural production. Neither is it reducible to white indulgence in Blacknessas-metaphor, that is, to white people imagining themselves as Black. Even though Blackness has been abstractified away from these dimensions in some respects, the jouissance of an improv-aeffect can ultimately be traced back to it. This concerns our libidinal hardwiring to the extent that we can be conscious of it. Consider what Newberg and Waldman write about language and consciousness:

If we want to understand the power of language and human communication, we have to include what we currently know about the nature of conscious thought. Consciousness [...] begins the moment we come out of the womb. Prior to birth the fetus is almost continuously asleep, with very little neural activity occurring in the areas that produce language. [...] Rapid neural growth begins immediately after we are born, as dense neural connections are made between the neocortex, the thalamus, and other deep structures of the brain. $(56-57)$

Two things are important here. First, it is safe to speculate that when we are developing our affective grammar for the world as infants, we do so not in terms of language, but in modes, modalities, or phenomena: that extra bit of geniality exuded by a friendly uncle when greeting the cousin's Black boyfriend or our mother's flushed cheeks when she comes back from her gospel choir rehearsal. Affective development by way of marking the world, though also linguistic, is prior to the development of verbal language. Second, we need to understand the development of the actual fabric, the physico-chemical structures of our consciousness in reciprocal relation with our affective learning and developing somatic markers prior to language, in images, gestures, and sounds. This is a difficult relationship to grasp. If consciousness creates an internal dichotomy between its rational (conscious) self and an abjected sphere marked by non-consciousness mapped onto Blackness, where exactly does our consciousness locate this non-conscious not-self so as to think about it? Within itself or outside itself? Is there any way consciousness can see itself in relation to a non-conscious space other than via the latter's containment, which destroys it? This is the depth of affective language at which we have arrived. I do not know how to further this thought. What I can say, though, is that the white improviser who acts 
on intuition, on his imagined natural self, his immediate self, unhindered by consciousness, is consciously aspiring to a natural, unintellectual, and unconscious (though stable) form of being discursively enshrined in the Black body as abjected space. The aim of white improvisers, whether explicit or implicit, conscious or unconscious, is to generate a somatic state in which they experience themselves as a coherent, unified whole, a smoothly functioning organism that automatically knows the next best thing to do.

I have considered Kristeva's subject-effect, modified as subject-aeffect, at several points in my argument. Up to this point, the reader may have interpreted it as a sensation that can also be achieved via anti-Black abjection of any intensity. As a consequence of the above discussion, I now claim that every subjectaeffect is anti-Black by discursive, affective, subjective necessity. Kristeva suggests that "out of such straying on excluded ground that [the one by whom the abject exists] draws his jouissance" (8). In the moment of abjective experience, the subject, attracted by the magnetic pull of the abject, lets himself into a state, a sphere, a "land of oblivion" where "the clean and proper (in the sense of incorporated and incorporable) becomes filthy." After and beyond, the abject, returning to the subject, generates a "flash of lightning" that "discharges like thunder" and unifies opposite worlds: "The time of abjection is double: a time of oblivion and thunder, of veiled infinity, and the moment when revelation bursts forth" (8-9). This "bursting forth" provides a kind of pure jouissance that does not merely correspond to but is the performance of intuition overcoming the split self of the modern white subject. The notion of "whiteface" is instructive here in order to examine white people's activities as they are grounded on our existential dependency on anti-Blackness. The term also highlights that Blackness as white people know it is a solipsist idea that has nothing to do with Black-racialized people. More, it plays ironically on the idea that we have made any progress; we no longer need to put on blackface and openly act or perform Black to experience that abjective sensation in the body. We are no longer even aware of where our doing comes from, what it originates in, what it means. (We must be wary of speculations like this one because they may feel like an intellectual closure on initial questions. Closure too is a white fantasy.) If we follow this through, play, as "the flow experience par excellence" (Csíkszentmihályi 151), offers a fertile ground to theorize this powerful somatic overlap, that is, the simultaneity and mutual reinforcement of overt and covert anti-Black abjection. I will elaborate on this idea in the following chapter. 